\title{
Đánh giá sơ bộ tiềm năng năng lượng thuỷ triều tại khu vực biển Cần Giờ-Tp. Hồ Chí Minh
}

\author{
Đinh Ngọc Huy ${ }^{*}$, Nguyễn Quốc Trinh ${ }^{2}$ \\ ${ }^{1}$ Trường Đại học Tài nguyên và Môi trường Tp.HCM; huyspb@gmail.com; \\ ${ }^{2}$ Trung tâm Dự báo khí tượng thủy văn quốc gia; maitrinhvinh @gmail.com \\ * Tác giả liên hệ: huyspb@gmail.com; Tel.: +84-942702208
}

Ban Biên tập nhận bài: 25/10/2020 Ngày phản biện xong: 28/12/2020 Ngày đăng bài: $25 / 1 / 2021$

Tóm tắt: Do nhu cầu sử dụng điện càng ngày càng gia tăng, nhiệt điện và thủy điện đang dần thể hiện sự hạn chế, nên vấn đề phát triển năng lượng tái tạo bắt đầu được chú trọng hơn trước đây. Trong bài báo này, chúng tôi lựa chọn vùng biển Cần Giờ của Thành phố Hồ Chí Minh (Tp.HCM) để đánh giá tiềm năng năng lượng thủy triều, do lợi thế gần vùng kinh tế lớn của cả nước và độ lớn thủy triều khoảng 3-4 m phù hợp phát triển điện triều. Bài báo này trình bày phương pháp nghiên cứu và đánh giá về tiềm năng điện triều bằng 2 phương án là đập thủy triều và năng lượng dòng triều. Các kết quả tính toán ban đầu xác định đối với các phương án khai thác điện bằng đập thủy triều công suất lớn nhất khoảng $224 \mathrm{MWh}$ và tổng điện năng khoảng xấp xỉ 1,14 tỷ $\mathrm{kWh} /$ năm. Và đối với năng lượng dòng triều tại các vị trí cửa sông Soài Rạp, Đồng Tranh, vịnh Gành Rái có tổng công suất khoảng 4,98-8,19 MW/m² với vận tốc dòng triều trung bình và khoảng $125-292 \mathrm{MW} / \mathrm{m}^{2}$ với vận tốc dòng triều cực đại. Kết quả nghiên cứu có thể phục vụ làm tài liệu tham khảo, làm tiền đề cho các nghiên cứu chi tiết cụ thể cho các công tác đánh giá chuyên sâu hơn tiềm năng năng lượng tái tạo trong tương lai trên vùng biển Tp.HCM nói riêng và các vùng biển khác nói chung.

Từ khóa: Thủy triều; Trạm điện thủy triều; Năng lượng tái tạo; Năng lượng dòng triều; Điện triều; Cần Giờ.

\section{1. Đặt vấn đề}

Trong điều kiện kinh tế nước ta đang phát triển mạnh, nhu cầu sử dụng tiêu thụ điện cũng gia tăng. Hiện nay, Chính phủ ban hành Chương trình hành động của Chính phủ thực hiện Nghị quyết số $55-\mathrm{NQ} / \mathrm{TW}$ ngày 11/2/2020 của Bộ Chính trị về định hướng Chiến lược phát triển năng lượng quốc gia của Việt Nam đến năm 2030, tầm nhìn đến năm 2045. Trong nghị quyết này cũng thể hiện rõ vai trò và sự cần thiết của các loại năng lượng tái tạo, trong đó có năng lượng thủy triều. Nguồn năng lượng thủy triều ở nước ta vẫn ở dạng tiềm năng sơ khai chưa có nhiều nghiên cứu. Mặc dù, nhiều quốc gia ven biển trên thế giới đã nghiên cứu, thiết kế và xây dựng thành công các trạm điện sử dụng năng lượng từ thuỷ triều hay gọi là trạm điện thủy triều (TĐTT) như Pháp (TĐTT La Rance), Nga (TĐTT Kislogubsk), Anh (dự án TĐTT Swansea), Canada (TĐTT Annapolis), Hàn Quốc (TĐTT hồ Sihwa, TĐTT Jindo Uldolmok), Scotland (dự án TĐTT MeyGen), Bắc Ireland (TĐTT SeaGen), Ân Độ (TĐTT Gujarat), Trung Quốc (TĐTT Jiangxia) ... đã chứng tỏ hiệu quả về kinh tế và góp phần vào giải quyêt các vấn đề an ninh năng lượng quốc gia [1].

Đối với Việt Nam, quốc gia có lợi thế với đường bờ biển dài trên $3260 \mathrm{~km}$ với độ lớn thủy triều trung bình có thể lên đến trên 3-4 m thì tiềm năng khai thác năng lượng thủy triều là rất khả thi. Bước đầu đã có những nghiên cứu, đánh giá sơ bộ về tiềm năng điện thủy triều, 
tiêu biểu như những tính toán về năng lượng thủy triều ở Biển Đông [2], kế đến là đánh giá sơ bộ về tiềm năng năng lượng thủy triều tại các cửa sông vùng biển Đông Nam Bộ (2011). Một số đề tài khoa học cũng có nghiên đề cập đến tiềm năng năng lượng biển Việt Nam như đề tài KC.09/2006-2010 do Nguyễn Mạnh Hùng làm chủ nhiệm, các đề tài khác của Viện Hàn lâm Khoa học và Công nghệ Việt Nam và Viện Năng lượng Việt Nam, ... Kết quả các nghiên cứu này đều chỉ ra rằng khu vực Vũng Tàu-Cần Giờ có tiềm năng khai thác năng lượng thủy triều rất đáng kể $[2,3]$.

Trong nghiên cứu này, nhóm tác giả lựa chọn khu vực nghiên cứu vùng biển Cần Giờ và lân cận (Hình 1 ) sử dụng các phương pháp phân tích và mô hình toán để mô phỏng quá trình thủy động lực, kết quả thu được sau đó sẽ làm số liệu đầu vào phục vụ tính toán với 02 phương án khai thác điện bằng đập thủy triều (ĐTT) và năng lượng dòng triều (NLDT) tại các vịnh và cửa sông ở khu vực này. Phương án ĐTT được sử dụng rộng rãi trong các dự án khai thác điện thuỷ triều tại các vùng cửa sông, cửa vịnh đã và đang được một số quốc gia trên thế giới áp dụng hiệu quả. Phương án NLDT được ứng dụng cho những vị trí khu vực có dòng chảy triều lớn và ổn định.

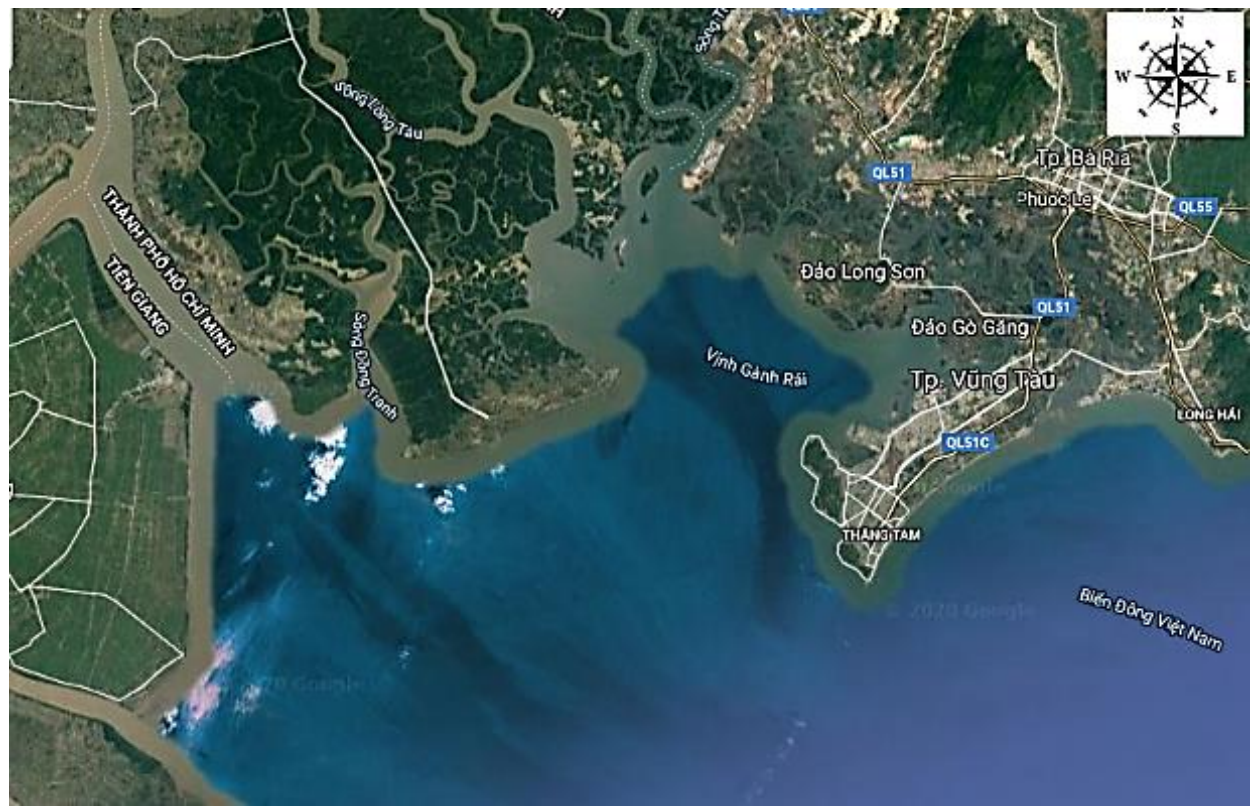

Hình 1. Vị trí khu vực biển Cần Giờ-Tp.HCM [4].

\section{Phương pháp nghiên cứu và thu thập tài liệu}

\subsection{Khu vực nghiên cứu}

Vùng biển Cần Giờ là vùng biển nằm phía Đông Nam thuộc Tp.HCM (Tp. HCM), cách trung tâm thành phố khoảng $50 \mathrm{~km}$ tính theo đường chim bay, là khu dự trữ sinh quyển thế giới, là lá phổi xanh cho Tp. HCM (Hình 1). Chiều dài bờ biển Cần Giờ khoảng $13 \mathrm{~km}$ tính từ mũi Đồng Tranh đến mũi Cần Giờ. Phía Đông Bắc của biển Cần Giờ là vịnh Gành Rái (từ Long Sơn đến mũi Cần Giờ), còn phía Tây Nam là vịnh Đồng Tranh (sông Soài Rạp đến mũi Đồng Hòa), vì vậy vùng biển ở đây được địa hình xung quanh che chắn và có bãi triều khá rộng lớn [5].

Huyện Cần Giờ nằm ở hạ lưu các con sông lớn như: Soài Rạp, Lòng Tàu, Thị Vải, Đồng Tranh, sông Dinh, là nơi có quá trình tương tác động lực sông-biển xảy ra mạnh mẽ. Địa hình đáy khu vực biển Cần Giờ biến đổi khá phức tạp từ vịnh Gành Rái-bờ biển Cần Giờ-vịnh Đồng Tranh với độ sâu từ vài mét cho đến khoảng $30 \mathrm{~m}$. Còn phía trong ở các con sông lớn như Soài Rạp, Lòng Tàu, Thị Vải-do thuộc hệ thống giao thông thủy huyết mạch của trung tâm kinh tế Tp.HCM và thường xuyên được nạo vét luồng hàng hải nên có độ sâu lớn nhất 
vào khoảng từ 30-60 m. Chế độ thủy triều ở vùng biển này thuộc loại bán nhật triều không đều với biên độ trung bình khá lớn có thể lên tới $4 \mathrm{~m}$, trong ngày có hai lần nước lên và hai lần nước xuống, chính vì vậy khu vực này được đánh giá là có tiềm năng khai thác năng lượng thủy triều [5].

\subsection{Phương pháp nghiên cúu}

Tiềm năng năng lượng thủy triều ở các khu vực ven biển được tính toán dựa trên sự trao đổi khối lượng nước vùng biển đó với đại dương trong một chu kỳ triều. Đối với nghiên cứu này, các phương án được đưa ra tính toán theo phương pháp đập thủy triều (ĐTT) và NLDT, chính vì thế cần phải xác định các yếu tố chính là: kích thước thủy vực phía trong đập triều; độ lớn triều và tốc độ dòng triều [6].

Nghiên cứu đã lựa chọn sử dụng phương pháp phân tích điều hòa và mô hình MIKE 21 FM làm mô hình truyền triều để tính toán dự báo thủy triều tại khu vực nghiên cứu, đồng thời ứng dụng lý thuyết kinh điển tính toán năng lượng thủy triều để đánh giá được tiềm năng có thể khai thác được ở đây.

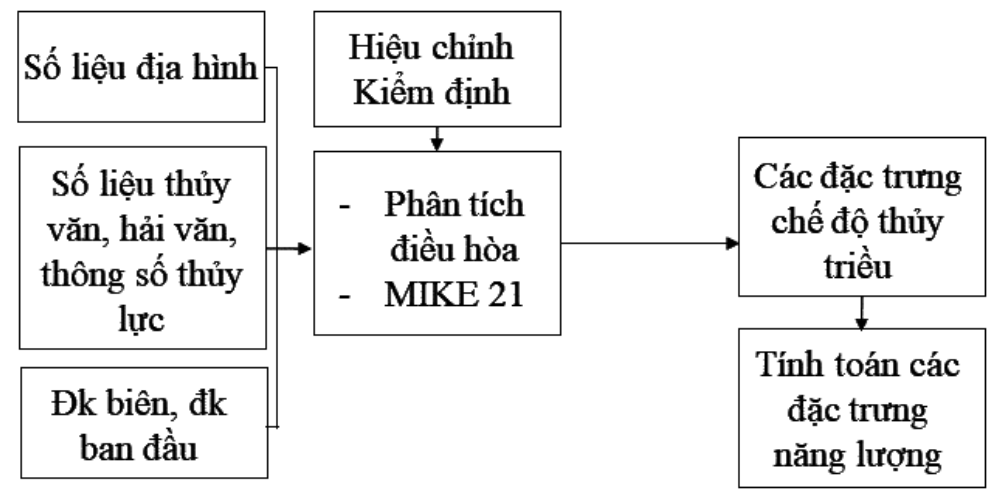

Hình 2. Quy trình thực hiện tính toán.

\subsection{Co sơ lý thuyết}

\subsubsection{Phương pháp phân tích điều hòa thủy triều}

Công thức để tính toán thuỷ triều theo phương pháp phân tích điều hoà được viết dưới dạng sau [7]:

$$
\mathrm{A}_{\mathrm{t}}=A_{0}+\sum_{i=1}^{n} f_{i} H_{i} \cos \left(q_{i} t+\left(V_{0}+u\right)_{i}-g_{i}\right)
$$

Trong đó $\mathrm{A}_{\mathrm{t}}$ là độ cao mực nước tại thời điểm $\mathrm{t}$; $\mathrm{A}_{0}$ là độ cao mực nước trung bình; $\mathrm{f}_{\mathrm{i}}$ là hệ số suy giảm biên độ; $H_{i}$ là biên độ phân triều; $q_{i}$ là tốc độ góc phân triều; $\left(\mathrm{V}_{0}+\mathrm{u}\right)_{\mathrm{i}}$ là hệ số biến đổi pha của phân triều; $g_{i}$ là góc vị của phân triều; $n$ là số phân triều.

Từ công thức (1) thi ta biến đổi cho thuận tiện để phân tích điều hoà bằng phương pháp bình phương tối thiểu. Nhóm các đại lượng biến thiên theo thời gian và không theo thời gian ký hiệu như sau:

$$
\begin{aligned}
a_{i} & =f_{i} \cos \left[q_{i} t+\left(V_{0}+u\right)_{i}\right] \\
X_{i} & =H_{i} \cos \left(g_{i}\right) \\
Y_{i} & =H_{i} \sin \left(g_{i}\right)
\end{aligned}
$$

kết hợp công thức (1) và (2) ta có công thức sau đây:

$$
A_{t}=A_{0}+\sum_{i}^{n}\left[\left(a_{i}\right)_{t} X_{i}+\left(b_{i}\right)_{t} Y_{i}\right]
$$


Nhiệm vụ là giải hệ phương trình (3) với số ẩn là $n$ bằng tổng các số đo gián đoạn của mực nước $\mathrm{A}_{\mathrm{t}}$ trong thời kỳ quan trắc. Từ đó phải tìm các ẩn là $\mathrm{A}_{0}, \mathrm{X}_{\mathrm{i}}, \mathrm{Y}_{\mathrm{i}}$ sau đó xác định các hằng số điều hoà của các phân triều như sau:

$$
\begin{aligned}
& H_{i}=\sqrt{X_{i}^{2}+Y_{i}^{2}} \\
& g_{i}=\operatorname{arctg}\left(\frac{Y_{i}}{X_{i}}\right)
\end{aligned}
$$

Việc giải hệ phương trình tuyết tính (4) để tìm $\mathrm{A}_{0}, \mathrm{X}_{\mathrm{i}}, \mathrm{Y}_{\mathrm{i}}$ bằng phương pháp bình phương tối thiểu và kết hợp với thuật toán Gauss.

\subsubsection{Mô hình MIKE21}

Dựa trên lý thuyết hệ phương trình thủy động lực phi tuyến, Viện Thủy lực Đan Mạch (DHI) đã phát triển bộ mô hình MIKE, trong đó có mô hình mô phỏng lan truyền sóng triều được sử dụng trong nghiên cứu như MIKE 21. Hệ phương trình sử dụng cho bài toán không gian hai chiều, gồm phương trình liên tục và 2 phương trình động lượng $[8,9]$ :

$$
\begin{aligned}
& \frac{\partial u}{\partial t}+u \frac{\partial u}{\partial x}+v \frac{\partial u}{\partial y}-f v=-g \frac{\partial \xi}{\partial x}-C_{b} \frac{u}{d}\left(u^{2}+v^{2}\right)^{1 / 2}+K\left(\frac{\partial^{2} u}{\partial x^{2}}+\frac{\partial^{2} v}{\partial y^{2}}\right) \\
& \frac{\partial v}{\partial t}+u \frac{\partial v}{\partial x}+v \frac{\partial v}{\partial y}+f u=-g \frac{\partial \xi}{\partial y}-C_{b} \frac{v}{d}\left(u^{2}+v^{2}\right)^{1 / 2}+K\left(\frac{\partial^{2} u}{\partial x^{2}}+\frac{\partial^{2} v}{\partial y^{2}}\right) \\
& \frac{\partial \xi}{\partial t}+u \frac{\partial d}{\partial x}+v \frac{\partial d}{\partial y}=0
\end{aligned}
$$

Trong đó $\mathrm{u}, \mathrm{v}$ là các thành phần dòng triều trung bình theo phương thẳng đứng theo các trục $\mathrm{x}$ và $\mathrm{y}$ tương ứng; $\xi$ là độ dâng mực nước trình bình; $\mathrm{f}$ là tham số Coriolis; $\mathrm{r}$ là hệ số ma sát; $h$ là độ sâu biển; $d$ là độ cao cột nước $(\mathrm{d}=\mathrm{h}+\xi) ; \mathrm{Cb}$ là hệ số ma sát đáy; $\mathrm{K}$ là hệ số nhớt rối theo phương ngang.

\subsubsection{Phương pháp tính toán công suất điện thủy triều sử dụng đập chắn}

Khi đó yếu tố chính để thể hiện công suất lắp đặt là diện tích thuỷ vực phía trong ĐTT và giá trị mực triều, dòng và áp lực có thể thu được từ tính toán sau khi điều chỉnh hay cân đối năng lượng thuỷ triều $[2,6]$.

Công sinh ra do thuỷ triều trong 1 chu kỳ triều lên xuống so với bề mặt tĩnh:

$$
P=\frac{A}{2} A S .10,05.10^{6}
$$

Trong đó $P$ là công sinh ra $(\mathrm{kJ}) ; A$ là mực triều $(\mathrm{m})$; $\mathrm{S}$ là diện tích thủy vực phía trong đập triều $\left(\mathrm{km}^{2}\right)$.

Công suất trung bình ngày $(\mathrm{kW})$ bằng công sinh ra do thủy triều trong một ngày chia cho số giây trong ngày:

$$
N_{p}=\frac{3,87 \cdot A^{2} \cdot S \cdot 10,05 \cdot 10^{6}}{2 \cdot 24 \cdot 3600}=225 A_{t b}^{2} \cdot S
$$

Giá trị này dùng để xác định dự trữ theo năm của tiềm năng điện bể TĐTT $(\mathrm{kWh})$ cho khu vực có thủy triều là bán nhật không đều (với D: tỷ số Vander-Stock):

$$
E_{t n}=1,97 \cdot 0,5 \cdot 10^{6} A_{t b}^{2} \cdot S \cdot\left(1+\frac{4-D}{D}\right)
$$

Điện năng kỹ thuật (Ekt) của năm có thể sử dụng vào phát điện năng của bể TĐTT là:

$$
E_{k t}=0,4 E_{t n}
$$


Trong đó $\mathrm{E}_{\text {tn }}$ là tổng điện năng tiềm năng. Công suất thiết kế kỹ thuật $(\mathrm{Nkt})$ của các TĐTT được tính bằng công thức:

$$
N_{k t}=250 \cdot A_{t b}^{2} S
$$

Tỷ lệ công suất thiết kế trên $1 \mathrm{~km}(\mathrm{Nkm})$ đê ngăn của ĐTT của các phương án được tính bằng công thức như sau:

Trong đó L là chiều dài đê ngăn của ĐTT.

$$
N_{k m}=N_{k t} / L
$$

\subsubsection{Phương pháp tính năng lượng dòng triều}

Sử dụng mô hình MIKE21 trình bày ở phần trên để tính toán dòng triều cho các vị trí đã chọn trước. Sau khi có vận tốc dòng triều, tiến hành tính mật độ năng lượng của dòng chảy cho một đơn vị diện tích tuabin vuông góc với hướng của dòng chảy theo công thức (3):

Trong đó $V$ là tốc độ dòng chảy trung bình.

$$
P_{m c}=0.5 \rho V^{3}
$$

Sử dụng công thức nêu trên đã tính phân bố NLDT cho các tháng đặc trưng cho các mùa khác nhau trong năm (tháng 4 và 10 ). Giá trị của năng lượng dòng chảy (công suất) tính bằng $\mathrm{W} / \mathrm{m}^{2}$.

\subsection{Cơ sở dũ liệu và thiết lập mô hình}

Số liệu sử dụng cho nghiên cứu này được thu thập từ những nguồn cung cấp dữ liệu chính xác, uy tín, hợp pháp, đảm bảo độ tin cậy và chính xác cao, bao gồm:

- Số liệu quan trắc đo đạc trong khu vực biển Tp.HCM từ các đề tài dự án qua các thời kỳ giai đoạn khác nhau;

- Số liệu mực nước đo đạc quan trắc tại trạm Vũng Tàu, Nhà Bè, Phú An, Hóa An, V.V...;

- Số liệu địa hình Hải quân Việt Nam, tỷ lệ 1/100.000; số liệu từ hệ thống dữ liệu đo đạc quốc tế GEBCO, ALOS, GMRT và SRTM; số liệu khảo sát địa hình từ đề tài, dự án trong khu vực nghiên cứu và lân cận.

Miền tính giới hạn trong khu vực $\left(10^{\circ} 08^{\prime} 42^{\prime \prime} \mathrm{N}-10^{\circ} 43^{\prime} 22^{\prime \prime} \mathrm{N} ; 1^{\prime} 6^{\circ} 38^{\prime} 42^{\prime \prime} \mathrm{E}-\right.$ $107^{\circ} 13^{\prime} 42^{\prime}$ "E), hệ thống lưới vuông $60 \mathrm{~m}$ x $60 \mathrm{~m}$ và toàn bộ miền tính được chia làm $1050 \mathrm{x}$ 1040 điểm tính với 06 biên lỏng, trong đó có 04 biên sông và 02 biên biển (Hình 3). Điều kiện biên là sử dụng bộ công cụ dự tính thủy triều của mô hình MIKE để thiết lập biên mực nước cho mô phỏng. Do là bài toán truyền triều nên nhóm nghiên cứu không đưa số liệu gió vào mô hình, các điều kiện ban đầu được thiết lập bằng " 0 ". Chiều dài đê biển và diện tích bể TĐTT được tính tương đối từ Google Earth, sơ đồ minh hoạ các vị trí đặt TĐTT và vị trí tính toán NLDT được thể hiện trên Hình 3. 


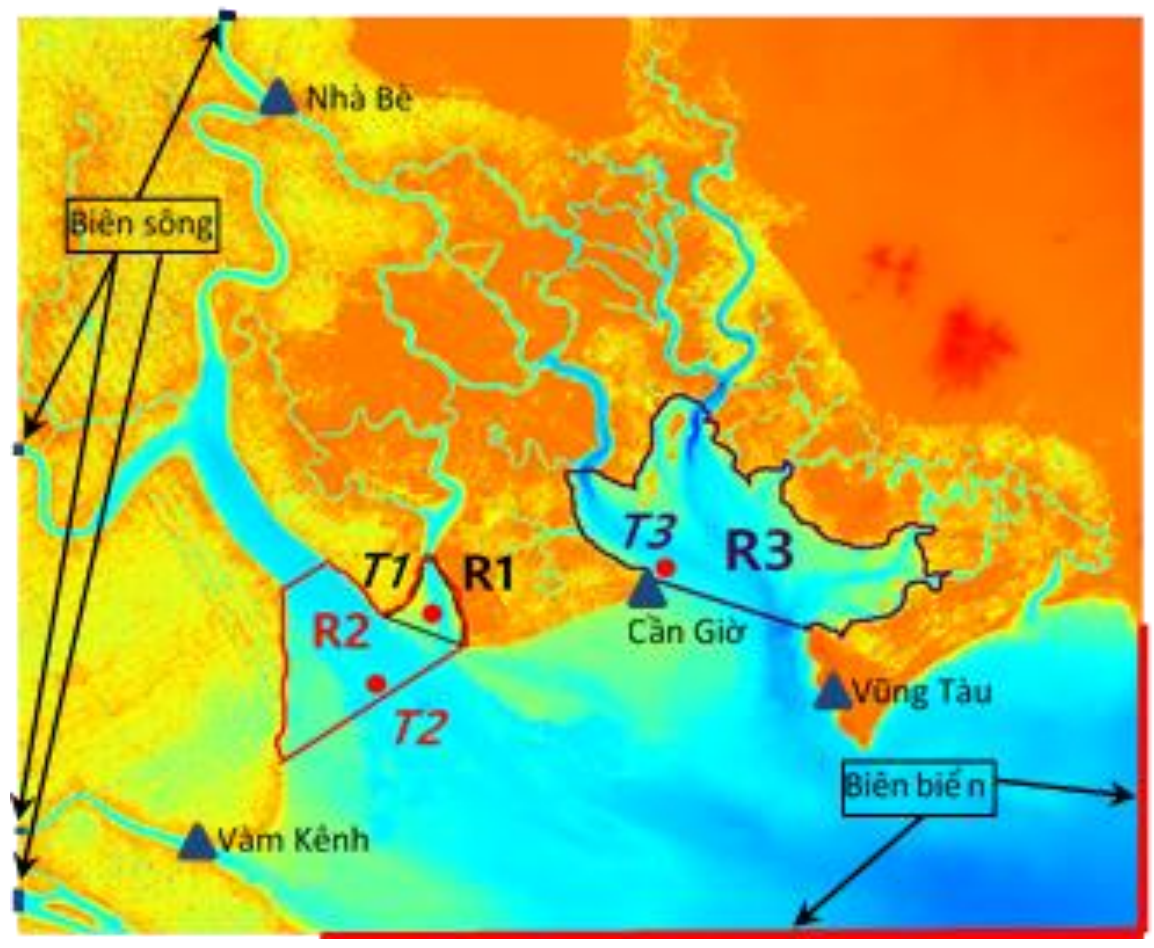

Hình 3. Vùng nghiên cứu với các vị trí phương án tính toán: Vị trí tính toán TĐTT: R1 (cửa sông Đồng Tranh); R2 (vịnh Đồng Tranh); R3 (vịnh Gành Rái); Vị trí tính toán NLDT: T1, T2. T3 tương ứng tại 3 khu vực có phương án TĐTT.

\section{Kết quả và thảo luận}

\subsection{Hiệu chỉnh và kiểm định}

Số liệu thu thập được xử lý chỉnh biên loại bỏ các sai số và số hóa, phục vụ phân tích điều hòa thủy triều, đồng thời cũng được sử dụng để đánh giá, hiệu chỉnh kết quả mô hình tính. Bằng việc phân tích điều hoà chuỗi mực nước, các hệ số biên độ và pha ban đầu của 08 sóng triều chính được xác định bằng phương pháp bình phương tối thiểu và được thể hiện trong Bảng 1 [9].

Bảng 1. Kết quả phân tích hằng số điều hòa các trạm.

\begin{tabular}{clcccccccccc}
\hline \multirow{2}{*}{ TT } & Tên & \multicolumn{2}{c}{ Vàm Kênh } & \multicolumn{2}{c}{ Nhà Bè } & \multicolumn{2}{c}{ Phú An } & \multicolumn{2}{c}{ Vũng Tàu } & \multicolumn{2}{c}{ Cần Giờ } \\
\cline { 2 - 11 } & sóng & $\mathrm{H}(\mathrm{cm})$ & Pha(độ) & $\mathrm{H}(\mathrm{cm})$ & $\mathrm{Pha}($ độ) & $\mathrm{H}(\mathrm{cm})$ & $\mathrm{Pha}($ độ) & $\mathrm{H}(\mathrm{cm})$ & Pha(độ) & $\mathrm{H}(\mathrm{cm})$ & Pha(độ) \\
\hline 1 & $\mathrm{~A} 0$ & $-4,60$ & & 0,82 & & 7,74 & & 262,53 & & 276,00 & \\
2 & $\mathrm{M} 2$ & 75,47 & 53,41 & 73,99 & 67,37 & 67,99 & 76,77 & 74,60 & 38,54 & 85,95 & 46,37 \\
3 & $\mathrm{~S} 2$ & 28,73 & 98,72 & 24,56 & 115,76 & 21,69 & 142,50 & 29,62 & 80,47 & 35,23 & 89,64 \\
4 & $\mathrm{~N} 2$ & 14,28 & 32,24 & 12,98 & 47,07 & 11,08 & 49,75 & 15,14 & 16,82 & 17,19 & 46,37 \\
5 & $\mathrm{~K} 2$ & 10,05 & 90,18 & 8,70 & 114,87 & 7,43 & 143,01 & 9,15 & 86,33 & 9,60 & 89,64 \\
6 & $\mathrm{~K} 1$ & 55,73 & 316,01 & 54,35 & 324,08 & 50,82 & 340,34 & 59,35 & 312,16 & 58,51 & 317,68 \\
7 & $\mathrm{O} 1$ & 40,49 & 278,60 & 38,64 & 282,31 & 35,25 & 274,57 & 44,12 & 269,72 & 43,58 & 264,35 \\
8 & $\mathrm{P} 1$ & 16,90 & 319,63 & 14,11 & 330,48 & 12,53 & 345,98 & 18,57 & 310,31 & 19,50 & 317,68 \\
9 & $\mathrm{Q} 1$ & 6,93 & 257,81 & 5,98 & 265,75 & 5,04 & 253,80 & 8,35 & 250,57 & 8,72 & 264,35 \\
\hline
\end{tabular}




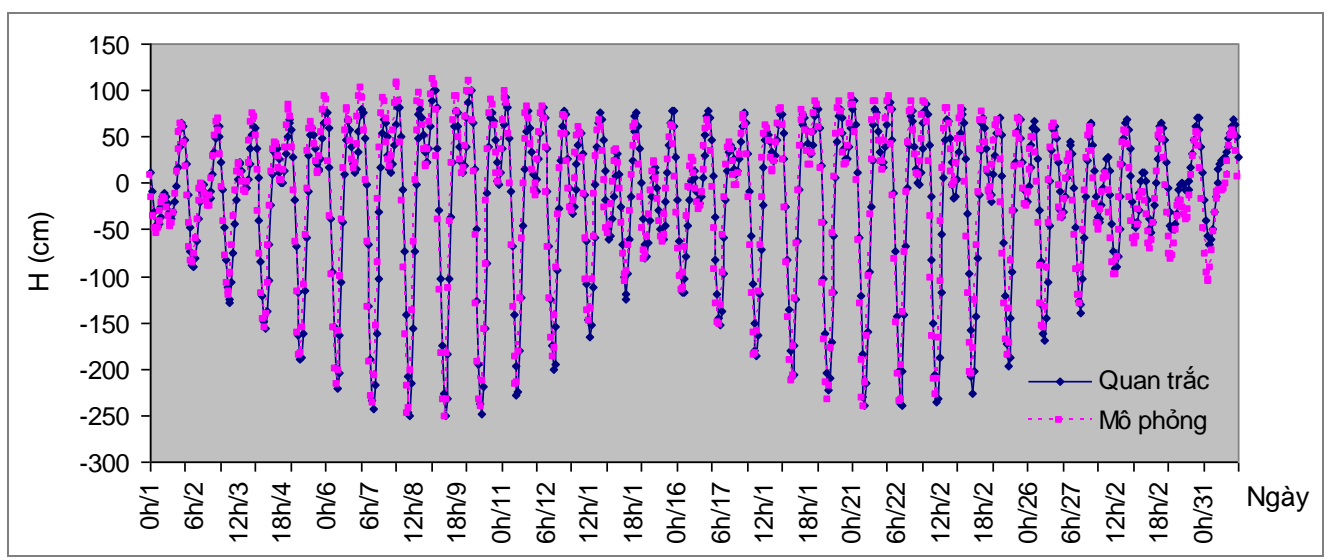

Hình 4. Mực nước mô phỏng và thực đo tháng 1/2007, trạm Vũng Tàu.

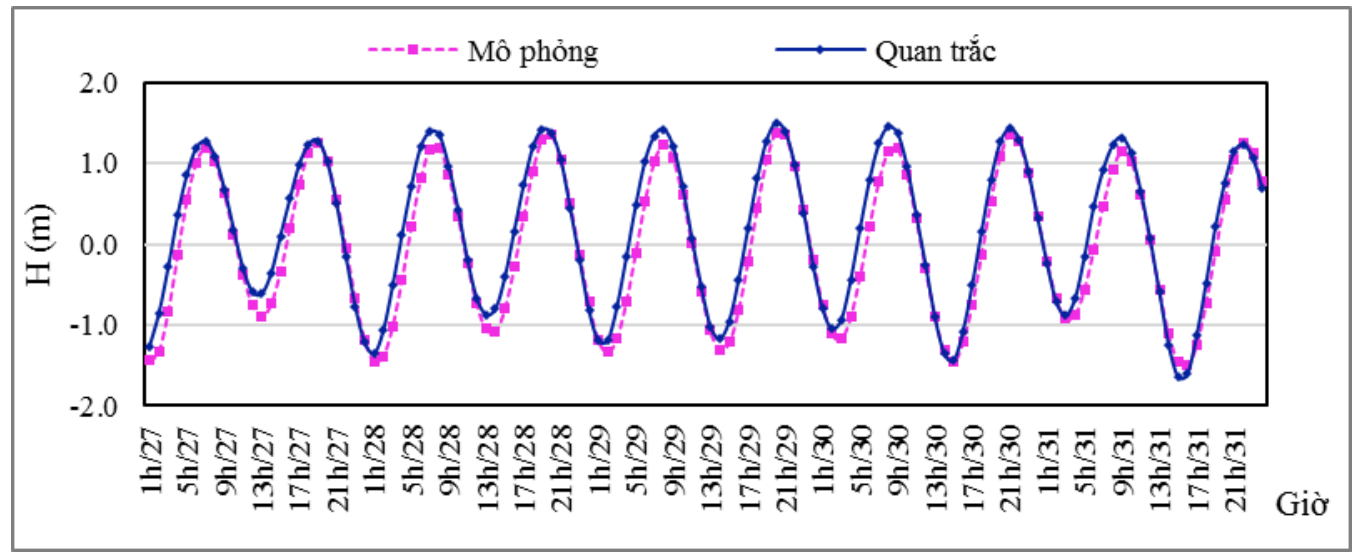

Hình 5. Mực nước mô phỏng và thực đo tháng 3/2017, trạm Vũng Tàu.

Bảng 1 cho thấy thể hiện về kết quả phân tích điều hòa từ các trạm hải văn, thủy văn và nghiệm triều thu nhận được giá trị mực nước trung bình $\left(\mathrm{A}_{0}\right)$ của trạm theo mốc trạm quy ước và hằng số điều của 08 phân triều chính. Giá trị $\mathrm{A}_{0}$ lớn vượt trội của trạm hải văn Vũng Tàu và trạm Cần Giờ là do mốc của 02 trạm này theo hải đồ và các trạm khác theo lục đồ (mốc "0" quốc gia). Trong đó, trạm thủy văn Phú An và trạm thủy văn Nhà Bè là trực tiếp trên khu vực thuộc Tp.HCM và các trạm còn lại là ảnh hưởng trực tiếp khu vực nghiên cứu.

Nghiên cứu đã sử dụng kết quả phân tích hằng số điều hòa để tiến hành hiệu chỉnh kiểm định cho mực nước triều tại các trạm Vũng Tàu, Nhà Bè, Vàm Kênh và Cần Giờ. Hình ảnh biến trình thủy triều của trạm Vũng Tàu được so sánh giữa thực đo và mô phỏng theo giờ giai đoạn hiệu chỉnh (tháng 1/2007) (Hình 4) và giai đoạn kiểm định (tháng 3/2017) (Hình 5) là phù hợp cả về pha và biên độ. Kết quả mô phỏng có độ tin cậy cao với hệ số tương quan $\mathrm{R}^{2}$ đều lớn hơn 0,90 trong cả hai giai đoạn hiệu chỉnh và kiểm định, điều này cho thấy rằng kết quả mô phỏng là rất tốt (Bảng 2).

Bảng 2. Kết quả hiệu chỉnh và kiểm định thủy lực trạm Vũng Tàu và một số trạm khác.

\begin{tabular}{|c|c|c|c|c|c|c|c|c|c|}
\hline \multirow[b]{2}{*}{ TT } & Tram & \multicolumn{2}{|c|}{ Vũng Tàu } & \multicolumn{2}{|c|}{ Nhà Bè } & \multicolumn{2}{|c|}{ Vàm Kênh } & \multicolumn{2}{|c|}{ Cần Giờ } \\
\hline & Thông số & $\begin{array}{l}\text { Hiệu } \\
\text { chỉnh }\end{array}$ & $\begin{array}{l}\text { Kiểm } \\
\text { dịnh }\end{array}$ & $\begin{array}{l}\text { Hiệu } \\
\text { chỉnh }\end{array}$ & $\begin{array}{l}\text { Kiểm } \\
\text { định }\end{array}$ & $\begin{array}{l}\text { Hiệu } \\
\text { chỉnh }\end{array}$ & $\begin{array}{c}\text { Kiểm } \\
\text { dịnh }\end{array}$ & $\begin{array}{l}\text { Hiệu } \\
\text { chỉnh }\end{array}$ & $\begin{array}{c}\text { Kiểm } \\
\text { định }\end{array}$ \\
\hline 1 & Tương quan $\left(\mathrm{R}^{2}\right)$ & 0,970 & 0,955 & 0,946 & 0,936 & 0,951 & 0,937 & 0,974 & 0,971 \\
\hline 2 & Sai số (cm) & 12,5 & 17,5 & 18,5 & 19,1 & 17,8 & 19,0 & 11,5 & 12,0 \\
\hline
\end{tabular}

Do ảnh hưởng của mực nước dâng do gió nên sai số này là chấp nhận được, hệ số xác định cho thấy các hằng số điều hòa tìm được có độ chính xác cao, đủ tin cậy để sử dụng tính toán dự báo triều tiếp theo cho các kịch bản và phương án tính toán điện thủy triều [10]. 


\subsection{Thời gian và vị trí tính toán}

Sau các bước hiệu chỉnh và kiểm cho kết quả phù hợp, nghiên cứu có được bộ thông số để tính toán các kịch bản cho năm 2020. Các kết quả tính toán mô phỏng này sẽ được sử dụng để làm dữ liệu đầu vào tính toán vào cho các phương án tiềm năng điện thủy triều (thường gọi là điện triều) theo cơ sở lý thuyết đã trình bày ở mục 3. Các phương án tính toán theo ĐTT và NLDT như Hình 3.

\section{Phương án 1: Cửa sông Đồng Tranh}

Vị trí phương án 1 là cửa sông Đồng Tranh đổ ra vịnh Đồng Tranh, tiếp giáp với cửa sông Soài Rạp. Phương án TĐTT này có diện tích thủy vực phía trong đập triều dự tính là $13,91 \mathrm{~km}^{2}$ với chiều dài tương đối của đập triều là $5 \mathrm{~km}$.

\section{Phương án 2: Vịnh Đồng Tranh}

Vị trí phương án 2 là vịnh Đồng Tranh, hạ lưu của sông Soài Rạp và sông Đồng Tranh đổ ra biển Đông. Phương án TĐTT này có diện tích thủy vực phía trong đập triều dự tính là $86,25 \mathrm{~km}^{2}$ với chiều dài tương đối của đập triều là $13,27 \mathrm{~km}$.

\section{Phương án 3: Vịnh Gành Rái}

Vị trí phương án 3 là vịnh Gành Rái, là vịnh có độ sâu khá lớn, là nơi đổ ra biển Đông của các con sông lớn như Ngã Bảy (Lòng Tàu), Thị Vải và sông Dinh. Phương án TĐTT này có diện tích thủy vực phía trong đập triều dự tính là $140,41 \mathrm{~km}^{2}$ với chiều dài tương đối của đập triều là 9,69 km.

\subsection{Kết quả và thảo luận}

Theo kết quả phân tích điều hòa 8 sóng triều tại các khu vực nghiên cứu, ta tính được giá trị D-tỷ số Vander-Stock thể hiện giá trị tính chất thủy triều cho 03 phương án (Bảng 3).

Bảng 3. Kết quả tính toán các tham số TĐTT tại khu vực biển Cần Giờ-Tp.HCM.

\begin{tabular}{ccccccccc}
\hline Vị trí & $\begin{array}{c}\mathbf{A}_{\mathbf{t b}} \\
\boldsymbol{c m}\end{array}$ & $\mathbf{D}$ & $\begin{array}{c}\mathbf{S} \\
\boldsymbol{k m}^{2}\end{array}$ & $\begin{array}{c}\mathbf{L} \\
\boldsymbol{k m}\end{array}$ & $\begin{array}{c}\mathbf{E}_{\mathbf{t n}} \\
(\boldsymbol{G} \boldsymbol{W h} / \boldsymbol{n} \breve{a} \boldsymbol{m})\end{array}$ & $\begin{array}{c}\mathbf{E}_{\mathbf{k t}} \\
(\boldsymbol{G} \boldsymbol{W h} / \boldsymbol{n a ̆ m})\end{array}$ & $\begin{array}{c}\mathbf{N}_{\mathbf{k t}} \\
(\boldsymbol{M W})\end{array}$ & $\begin{array}{c}\mathbf{N}_{\mathbf{k}} / \mathbf{L} \\
(\boldsymbol{M W / k m})\end{array}$ \\
\hline $\mathrm{R} 1$ & 264,1 & 1,30 & 13,91 & 5 & 294,4 & 117,7 & 24,3 & 4,9 \\
$\mathrm{R} 2$ & 265,5 & 1,31 & 86,25 & 13,27 & 1812,3 & 724,9 & 150,9 & 11,4 \\
$\mathrm{R} 3$ & 266,2 & 1,35 & 140,41 & 9,69 & 2860,3 & 1144,1 & 244,8 & 25,3 \\
\hline
\end{tabular}

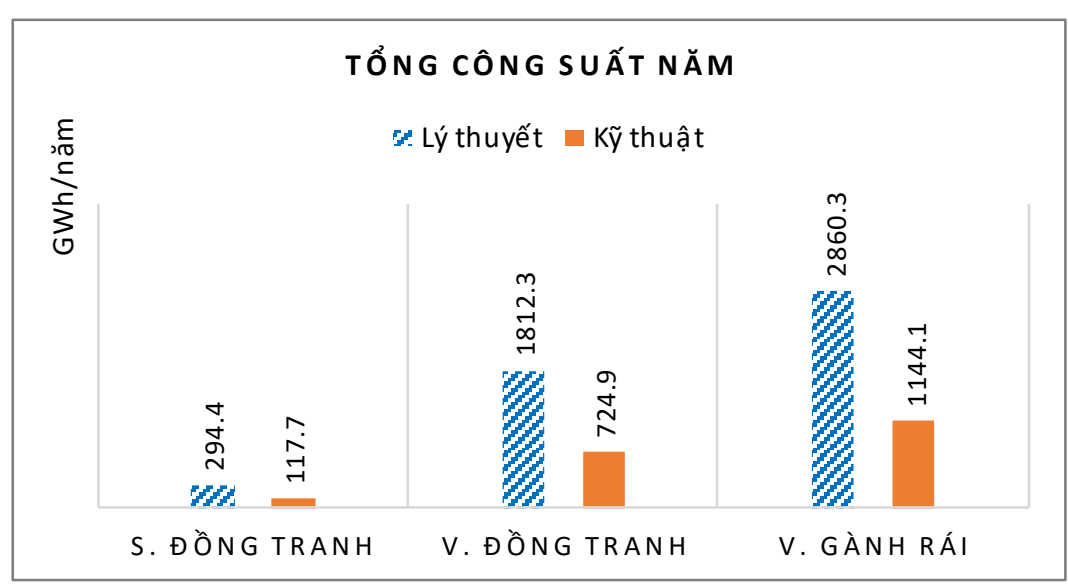

Hình 6. Tổng công suất năm lý thuyết và kỹ thuật tại 03 vị trí phương án TĐTT. 

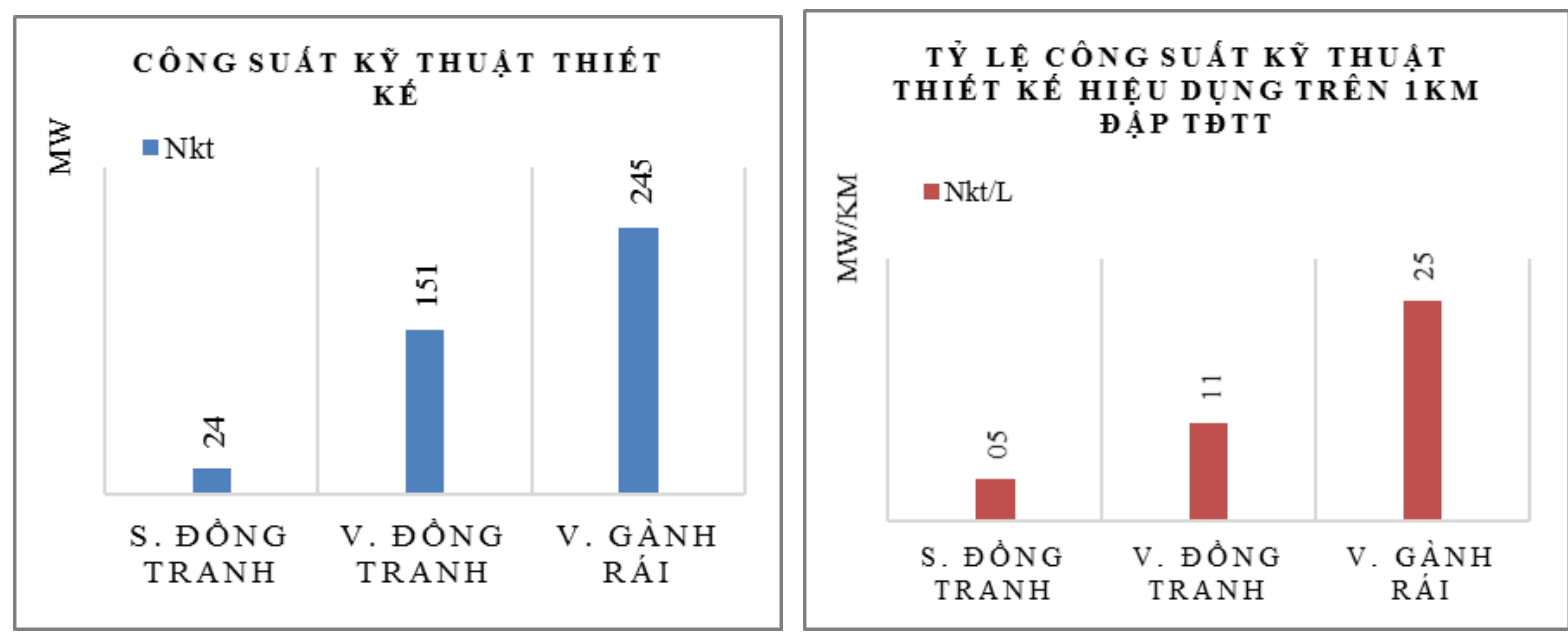

Hình 7. Công suất kỹ thuật và tỷ lệ hiệu dụng trên $1 \mathrm{~km}$ chiều dài đê ngăn bể tại 03 vị trí TĐTT.

Theo kết quả tính toán được thể hiện trên Bảng 3 và Hình 6 , ta thấy được tổng công suất lý thuyết và thiết kế của 03 vị trí có phương án đặt ĐTT. Dễ thấy rằng phương án 3 tại vịnh Gành Rái có tiềm năng cao nhất. Công suất trung bình tại đây là $244.8 \mathrm{MWh}$, tổng công suất kỹ thuật (giả định tối đa đạt $40 \%$ công suất lý thuyết) vào khoảng $1144 \mathrm{GWh}(1,14$ tỷ $\mathrm{kWh}$ ). Lý do ở đây ngoài mực triều trung bình có giá trị cao nhất thì do phương án tại vịnh Gành Rái được đưa ra với diện tích thủy vực phía trong ĐTT lớn nhất.

Phương án thấp nhất là tại cửa sông Đồng Tranh với công suất trung bình chỉ $24 \mathrm{MWh}$ và tổng công suất kỹ thuật là $118 \mathrm{GWh}$. Lý do là phương án này có diện tích thủy vực rất nhỏ, tuy nhiên tiềm năng phát điện thủy triều là có. Đối với phương án 2 tại vịnh Đồng Tranh, công suất trung bình và tổng công suất kỹ thuật nhỏ hơn so với tại vịnh Gành Rái (151 MWh và $725 \mathrm{GWh}$ ) do diện tích thủy vực nhỏ. Tuy nhiên chiều dài đê ngăn của ĐTT ở đây lại dài nhất $(13,27 \mathrm{~km})$ trong số 3 phương án. Dễ thấy rằng nếu so sánh tỷ lệ công suất hiệu dụng thiết kế trên $1 \mathrm{~km}$ đê ngăn của ĐTT thì tại vịnh Gành Rái với giá trị $25 \mathrm{MW} / \mathrm{km}$ đạt hiệu quả kinh tế cao nhất (Hình 7).

Bảng 4. Kết quả tính toán NLDT tại khu vực biển Cần Giờ-Tp.HCM với vận tốc trung bình và vận tốc cực đại.

\begin{tabular}{|c|c|c|c|c|c|}
\hline \multirow[t]{2}{*}{ Thời gian } & \multirow{2}{*}{$\frac{\text { Vị trí }}{\text { R1 }}$} & \multirow{2}{*}{$\begin{array}{c}\begin{array}{c}\mathrm{V}_{\text {tb }} \\
\boldsymbol{c m} / \boldsymbol{s}\end{array} \\
22,91\end{array}$} & \multirow{2}{*}{$\begin{array}{c}\mathrm{V}_{\max } \\
\mathrm{cm} / \mathrm{s} \\
66,67\end{array}$} & \multicolumn{2}{|c|}{$\begin{array}{c}\mathbf{P}_{\mathrm{mc}} \\
\left(W / m^{2}\right)\end{array}$} \\
\hline & & & & 6,14 & 151,15 \\
\hline \multirow[t]{3}{*}{ Tháng 4} & $\mathrm{R} 2$ & 25,22 & 83,04 & 8,19 & 292,30 \\
\hline & R3 & 23,42 & 60,68 & 6,56 & 114,02 \\
\hline & $\mathrm{R} 1$ & 21,37 & 52,95 & 4,98 & 75,8 \\
\hline \multirow[t]{2}{*}{ Tháng 10} & $\mathrm{R} 2$ & 23,43 & 62,53 & 6,56 & 124,8 \\
\hline & R3 & 22,01 & 59,8 & 5,44 & 109,2 \\
\hline
\end{tabular}

Nghiên cứu cũng đã mô phỏng tính toán vận tốc dòng triều trung bình và cực đại vào thời gian 2 mùa (mùa khô-tháng 4 và mùa mưa-tháng 10 ) và mật độ NLDT tương ứng tại 03 vị trí đã lựa chọn (Bảng 4 và Hình 8 ). Do trong khuôn khổ bài báo này nhóm nghiên cứu chỉ đánh giá tiềm năng NLDT nên không tính toán đến dòng dư trong mô hình.

Tại vị trí cửa sông Đồng Tranh và vịnh Gành Rái có giá trị mật độ năng lượng (công suất) gần tương ứng nhau do lựa chọn tính toán dòng triều ở vịnh Gành Rái là vị trí gần bờ, lần lượt đạt $6,14 \mathrm{MW} / \mathrm{m}^{2}$ và $6,56 \mathrm{MW} / \mathrm{m}^{2}$ (tháng 4$) ; 4,98 \mathrm{MW} / \mathrm{m}^{2}$ và $5,44 \mathrm{MW} / \mathrm{m}^{2}$ (tháng 10 ). Tiềm năng nhất là tại vị trí vịnh Đồng Tranh (cửa sông Soài Rạp) với giá trị mật độ năng lượng đạt $8,19 \mathrm{MW} / \mathrm{m}^{2}$ (tháng 4) và $6,56 \mathrm{MW} / \mathrm{m}^{2}$ (tháng 10 ). 


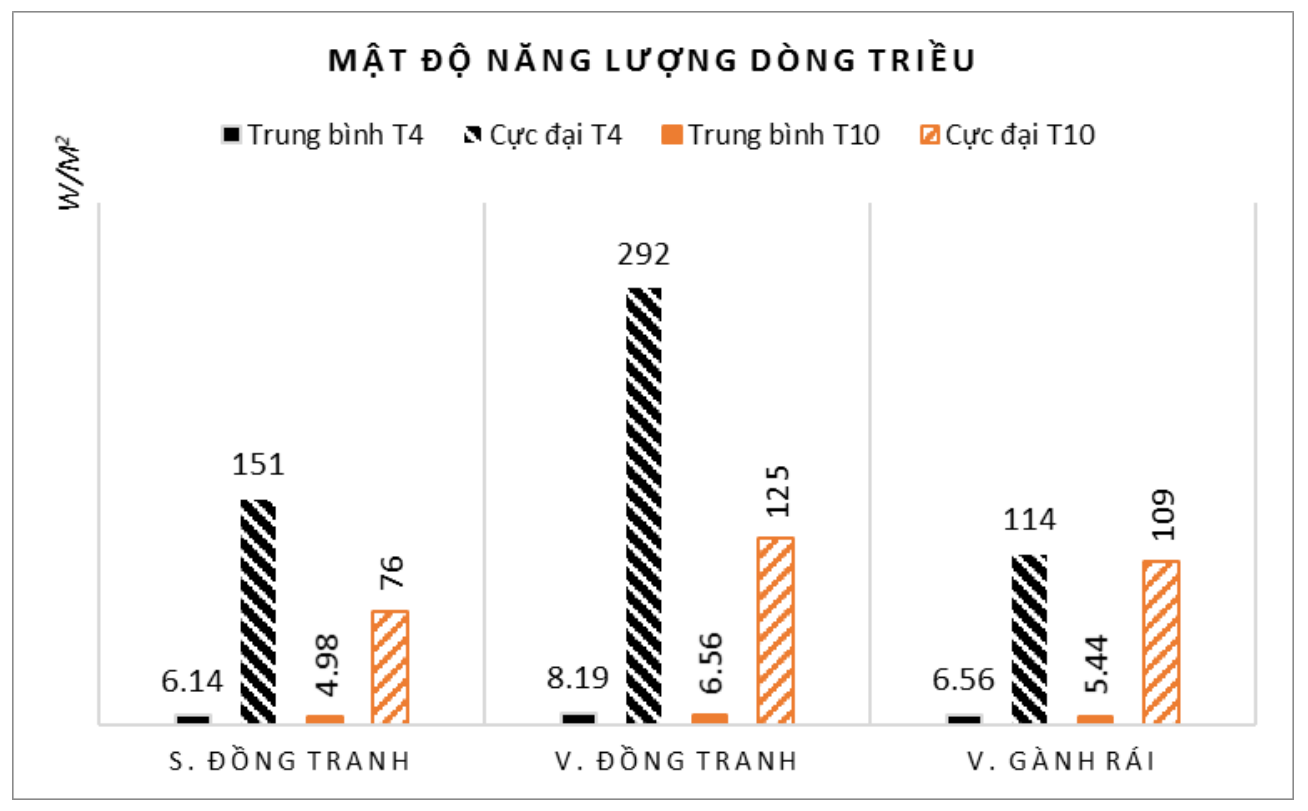

Hình 8. Mật độ NLDT trung bình và cực đại tại 03 vị trí TĐTT.

Kết quả cũng tương tự đối với trường hợp tính toán cho vận tốc dòng triều cực đại, khu vực vịnh Đồng Tranh (cửa sông Soài Rạp) cho công suất cao nhất lần lượt là $292 \mathrm{MW} / \mathrm{m}^{2}$ (tháng 4) và $125 \mathrm{MW} / \mathrm{m}^{2}$ (tháng 10 ). Điều này cho thấy năng lượng từ dòng triều tại khu vực biển Cần Giờ rất có tiềm năng khai thác.

\section{Kết luận}

Bài báo này đã tiến hành nghiên cứu và đánh giá tiềm năng về năng lượng thủy triều ở vùng biển Cần Giờ và lân cận. Các kết quả tính toán phân tích và mô phỏng được trình bày:

- Sử dụng từ các số liệu mực nước quan trắc để phân tích để làm cơ sở so sánh đánh giá. Độ lớn thủy triều tại các trạm dao động khoảng từ $2,5 \mathrm{~m}$ đến trên $4,0 \mathrm{~m}$;

- Mô hình MIKE được sử dụng rộng rãi và phổ biến ở trong nước và thế giới. Các kết quả so sánh giữa mô hình và quan trắc là đảm bảo với độ chính xác cao phổ biến trên $90 \%$.

Các kết quả tính toán ban đầu xác định đối với các phương án ĐTT công suất lớn nhất khoảng $224 \mathrm{MWh}$ và tổng điện năng khoảng xấp xỉ 1,14 tỷ $\mathrm{kWh} /$ năm. Và đối với NLDT tại các vị trí cửa sông Soài Rạp, Đồng Tranh, vịnh Gành Rái có tổng công suất khoảng 4,98-8,19 $\mathrm{MW} / \mathrm{m}^{2}$ với vận tốc dòng triều trung bình và khoảng $125-292 \mathrm{MW} / \mathrm{m}^{2}$ với vận tốc dòng triều cực đại.

Vấn đề gặp phải ở đây là tại các vị trí lựa chọn để tính toán tiềm năng điện triều có vịnh Gành Rái và vịnh Đồng Tranh (cửa sông Soài Rạp) đều là tuyến hàng hải huyết mạch của cụm kinh tế Tp.HCM và Đông Nam Bộ.

Đối với khu vực vịnh Đồng Tranh, nếu xây dựng theo phương án ĐTT tại đây thì phương án 1 cửa sông Đồng Tranh sẽ ít gây ảnh hưởng tới tuyến hàng hải sông Soài Rạp nhất. Tuy phương án này có công suất phát điện thấp nhất nhưng có thể lại là phương án được xem xét là khả thi nhất. ĐTT khi được xây dựng ở đây có ưu điểm không tạo ra khí thải nhà kính, tăng cường giao thông, cải thiện thủy lợi, v.v... tuy nhiên sẽ có ảnh hưởng lớn đến quá trình lắng đọng trầm tích, đến hệ sinh thái bãi triều và rừng ngập mặn tại khu vực Vàm Sát. Vì vậy, phương án NLDT tại khu vực này là phù hợp hơn phương án ĐTT với ưu điểm là lựa chọn vị trí đặt các tuabin tiện lợi hơn so với xây dựng đập ngăn, tránh được ảnh hưởng tới luồng hàng hải và hệ sinh thái bãi triều, rừng ngập mặn. 
Đối với khu vực vịnh Gành Rái, phương án ĐTT tại đây có tiềm năng rất lớn, tuy nhiên nó cũng sẽ gây ảnh hưởng tới hai tuyến hàng hải sông Thị Vải và sông Lòng Tàu. Để khắc phục vấn đề nêu trên, chúng ta có thể xem xét đề xuất phương án xây dựng ĐTT tại khu vực đảo Long Sơn-đảo Gò Găng (Bà Rịa-Vũng Tàu). ĐTT ở đây tuy có diện tích thuỷ vực phía trong đập nhỏ hơn đồng nghĩa với công suất tiềm năng điện triều giảm xuống, nhưng sẽ tránh được ảnh hưởng tới giao thông thuỷ và khu vực rừng ngập mặn của khu dự trữ sinh quyển Cần Giờ. Ngoài ra phương án NLDT tại khu vực này cũng sẽ có tiềm năng lớn để phát triển với các điều kiện thuận lợi như: dòng triều mạnh, vịnh Gành Rái là khu vực rộng lớn và có ưu điểm trong việc lựa chọn vị trí phù hợp đặt các tuabin. Năng lượng thuỷ triều được đánh giá là nguồn năng lượng vĩnh cửu và thân thiện với môi trường nên trong tương lai sẽ cần những đánh giá chuyên sâu hơn về bài toán hiệu quả kinh tế-xã hội khi xây dựng trạm điện thuỷ triều nơi đây.

Kết quả đạt được từ nghiên cứu này có thể phục vụ làm tài liệu tham khảo, làm tiền đề cho các nghiên cứu chi tiết cụ thể cho các công tác đánh giá chuyên sâu hơn tiềm năng năng lượng tái tạo trong tương lai trên vùng biển $\mathrm{Tp}$.HCM nói riêng và các vùng biển khác nói chung.

Lời cám ơn: Nghiên cứu được thực hiện bằng nguồn kinh phí hỗ trợ từ Chương trình Vườn ươm Sáng tạo Khoa học và Công nghệ Trẻ, được quản lý bởi Trung tâm Phát triển Khoa học và Công nghệ Trẻ-Thành Đoàn Tp.HCM và Sở Khoa học và Công nghệ Tp.HCM, theo hợp đồng số "21/2019/HĐ-KHCN-VU'".

Lời cam đoan: Tập thể tác giả cam đoan bài báo này là công trình nghiên cứu của tập thể tác giả, chưa được công bố ở đâu, không được sao chép từ những nghiên cứu trước đây; không có sự tranh chấp lợi ích trong nhóm tác giả.

\section{Tài liệu tham khảo}

1. Online: https://www.power-technology.com/features/featuretidal-giants-the-worldsfive-biggest-tidal-power-plants-4211218/.

2. Toán, D.V. Năng lượng thủy triều biển Đông. Tạp chí Khoa học và Công nghệ biển 2015, $1,1-12$.

3. Hùng, N.M. và cs. Điều tra đánh giá tiềm năng các dạng Năng lượng biển chủ yếu và đề xuất các giải pháp khai thác. Đề tài KC.09/2006-2010, 2010.

4. Online: https://www.google.com/earth/

5. Hoặc, P.V. Nghiên cứu tương tác động lực học biển sông ven biển Cần giờ phục vụ xây dựng cơ sở hạ tầng cho du lịch sinh thái Tp.HCM. Viện Khí tượng Thủy văn Hải văn \& Môi truò̀ng, Tp.HCM, 2004.

6. Berstien, L.B. và cs. Trạm điện thủy triều. NXB Viện thiết kế thủy lợi, Moskva, 1994, tr. 596 (tiếng Nga).

7. Huấn, P.V. Tính toán trong hải dương học. NXB ĐH Quốc gia Hà Nội, 2003.

8. Bay, N.T.; Phung, N.K. Study on the tendency of accretion and erosion in the Can Gio coastal zone. J. Marine Sci. Technol. 2007, 7. https://doi.org/10.15625/18593097/7/4/6354.

9. User manual MIKE 21, 2007.

10. Bảng thuỷ triều 2005, 2006, 2007. Tập II. Trung tâm khí tượng thủy văn quốc gia. 


\title{
Preliminary assessment of tidal energy potential in the Can Gio coastal area, Ho Chi Minh city
}

\author{
Dinh Ngoc Huy ${ }^{1 *}$, Nguyen Quoc Trinh ${ }^{2}$ \\ ${ }^{1}$ Ho Chi Minh City University of Natural Resources and Environment; huyspb@gmail.com; \\ ${ }^{2}$ National Centre for Hydro-Meteorological Forecasting; maitrinhvinh@ gmail.com
}

\begin{abstract}
Abtract: Due to the increasing demand for electricity, thermal and hydroelectricity is showing increasing limitation. So the issue of renewable energy is starting to be more focused than before. In this article, we choose the Can Gio zone of Ho Chi Minh City to assess the tidal energy potential, due to the advantage of proximity to the large economic region of the country and the magnitude of the tides about 3-4 m, suitable for tidal power development. This paper presents research methodology and evaluation of tidal power potential by 2 alternatives: tidal basin power and tidal current energy. The initial calculation results determined that the largest capacity tidal basin power plan is about $224 \mathrm{MWh}$ and the total power is approximately 1.14 billion $\mathrm{kWh} / \mathrm{year}$. And for tidal current energy at the estuaries of Soai Rap, Dong Tranh, Ganh Rai and Soai Rap estuaries, there are about 4.98$8.19 \mathrm{MW} / \mathrm{m}^{2}$ and total capacity of about $125-292 \mathrm{MW} / \mathrm{m}^{2}$ with maximum tidal current velocity. The results of the research can serve as a reference, as a premise for detailed studies for more in-depth assessment of the renewable energy potential in the Can Gio zone of HCMC said own and other waters in general in the future.
\end{abstract}

Keywords: Tide; Renewable energy; Tidal energy; Tidal basin power; Tidal current energy; Can Gio zone. 